\title{
Prevalência de paracoccidioidomicose-infecção determinada através de teste sorológico em doadores de sangue na região Noroeste do Paraná, Brasil
}

\author{
Prevalence of paracoccidioidomycosis infection determined by \\ sorologic test in donors' blood in the \\ Northwest of Paraná, Brazil. \\ Márcia Luzia Ferrarezi Maluf' Sandra Regina Corbello Pereira1 \\ Gisele Takahachi' ${ }^{1}$ Terezinha Inez Estivalet Svidzinski ${ }^{2}$
}

\begin{abstract}
Resumo No presente trabalho, empregamos uma metodologia de alta sensibilidade, o teste de ELISA clássico, com o objetivo de avaliar os níveis de anticorpos anti Paracoccidioides brasiliensis em indivíduos saudáveis, residentes na região Noroeste do Paraná. Foram analisados 680 soros de doadores de sangue aprovados pela triagem sorológica clássica de Bancos de Sangue. Os doadores eram residentes em quatro municípios. $O$ exo-antígeno empregado foi o Ag7dias, soros diluídos 1/400, conjugado anti-lgG humana marcada com peroxidase e revelada com orto-fenilenodiamina. Foi possível detectar 181 (27\%) soros com níveis de anticorpos acima do valor de corte. Essa porcentagem variou entre os municípios amostrados: Campo Mourão, Maringá, Cianorte e Umuarama. Nossos resultados, aliados às condições climáticas e geográficas favoráveis, além de relatos anteriores de casos de PCM autóctones da região, permitem sugerir que a região Noroeste do Paraná seja região endêmica para PCM.
\end{abstract}

Palavras-chaves: Paracoccidioidomicose. Epidemiologia. ELISA. Paracoccidioides brasiliensis.

Abstract In this paper the classical ELISA test was used, which is a highly sensitive method, with the objective of estimating the anti-Paracoccidioides brasiliensis antibodies level in healthy people, residing in supposedly endemic regions for PCM, Northwest Paraná State, Brazil. The sera was analyzed from 680 blood donors' who were approved by the classical serologic screening by blood banks. Four cities were studied (Campo Mourão, Maringa, Cianorte and Umuarama) with a sample of 170 donors each. The antigen used was Ag7days, diluted serum 1/400, anti human IgG-conjugate marked with peroxidase and revealed with O-Phenylenediamine. It was possible to detect 181 (27\%) sera with antibody level above the cut off threshold. The percentage varied between the cities. These results allied with the favorable climatic and geographical conditions and also previous reports of PCM indigenous to the region, indicate that the Northwest of Paraná is an endemic region for PCM. Key-words: Paracoccidioidomycosis. Epidemiology. ELISA. Paracoccidioides brasiliensis.

Paracoccidioidomicose (PCM) é uma doença granulomatosa crônica causada pelo fungo termicamente dimórfico Paracoccidioides brasiliensis. É considerada a micose sistêmica mais importante na América Latina ${ }^{3}$ sendo, prevalente nas regiões tropicais e subtropicais. O Brasil é considerado um centro endêmico dessa infecção micótica, onde a sua ocorrência é maior nas regiões Sul, Sudeste e Centro-Oeste ${ }^{9}$.
A infecção é adquirida pela via respiratória, através da inalação de partículas ou propágulos infectantes ${ }^{10}$. Têm sido descritos alguns aspectos epidemiológicos relacionados com as condições nas quais o homem pode adquirir a infecção e, de maneira geral estão associados à participação permanente ou transitória em atividades rurais, sejam de trabalho, viagem ou lazer. Porém, é impossível precisar o momento e a circunstância do contato entre o homem e o agente ${ }^{1215}$.

\footnotetext{
1. Lamoratório de Ensino e Pesquisa em Análises Clínicas do Hemocentro Regional de Maringá, Maringá, PR. 2. Disciplina de Micologia Médica do Departamento de Análises Clínicas da Universidade Estadual de Maringá, Maringá, PR.

Endereço para correspondência: Profa. Terezinha Inez Estivalet Svidzinski. R. Júlio Favoretto 35, Vila Esperança, 87020-600 Maringá, PR. Tel: 44 263-1387.

e-mail: tiesvidzinski@uem.br ou terezinha@email.com

Recebido para publicação em 23/7/2001.
} 
A PCM acomete mais freqüentemente adultos, trabalhadores rurais, do sexo masculino ${ }^{8}$, e muitas vezes, resulta em seqüelas irreversíveis que incapacitam o indivíduo para o trabalho. Sem intervenção terapêutica específica o paciente evolui para o óbito. Essas complicações implicam em elevados custos sociais e econômicos, além de caracterizar a doença como de alta relevância em saúde pública, justificando a necessidade de estabelecer diagnóstico tão precoce quanto possível .

O presente estudo foi realizado com o objetivo de determinar os níveis de anticorpos anti- $P$. brasiliensis em doadores de sangue e avaliar a possibilidade da aplicação do teste de ELISA para a detecção de PCM infecção.

\section{MATERIAL E MÉTODOS}

Este trabalho envolveu doadores de sangue residentes em quatro municípios da Região Noroeste do Paraná e foi realizado no Hemocentro Regional de Maringá, PR. Este, constitui-se em unidade de complexidade intermediária para atuação macroregional na área hemoterápica-hematológica, presta apoio e assistência à rede de saúde e também realiza atividades de ensino e pesquisa. É encarregado da supervisão dos serviços e a realização dos exames sorológicos de todas as unidades de coleta. Campo Mourão é um hemonúcleo, enquanto Cianorte e Umuarama, são unidades de coleta e transfusão que prestam assistência hemoterápica a nível local. Os quatro municípios em conjunto totalizam uma área de $3.300,00 \mathrm{~km}^{2}$ e população de 517.000 habitantes ${ }^{7}$.

Foram analisadas 680 amostras de soro de doadores de sangue residentes na Região Noroeste que foram aceitos na triagem clínica. Todos tinham sorologia negativa para os exames de hepatite (B e C), anti-HTLV, sífilis, doença de Chagas e anti-HIV. Após a coleta da bolsa de sangue, foi obtida uma amostra de $10 \mathrm{ml}$ de sangue sem anticoagulante, que foi incubada a $37^{\circ} \mathrm{C}$ durante 30 minutos, em seguida centrifugada a $400 \mathrm{xg}$ por 10 minutos, obtendo-se o soro que foi congelado a $-20^{\circ} \mathrm{C}$ até a realização dos testes.

Durante o mês de março de 2000, os primeiros 170 doadores de cada município que preenchiam as condições citadas acima, foram incluídos no presente trabalho.

A metodologia empregada foi o teste de ELISA clássico. Foram utilizados como referencial para controle negativo soros de 30 doadores de sangue provenientes da área urbana de Curitiba, PR. Considerou-se que esse grupo teria menor probabilidade de exposição ao fungo por residir em área considerada de menor risco. Para o controle positivo, foram utilizados soros de pacientes comprovadamente reativos.

O exo-antígeno de $P$. brasiliensis B339 utilizado foi um filtrado de cultura do fungo que apresentava a molécula de $43 \mathrm{Kda}$ em expressiva quantidade. Essa, é conhecida como gp43 e corresponde ao componente antigênico majoritário excretado para meios de cultura ${ }^{4}$.

Para a realização do teste de ELISA, utilizaram-se placas da marca (NUNC) com 96 poços que foram sensibilizadas com exo-antígeno de P. brasiliensis. Para a sensibilização, as placas foram incubadas com $200 \mu \mathrm{l}$ do exo-antígeno por duas horas, a $37^{\circ} \mathrm{C}$ e mantidas por 18 horas a $4^{\circ} \mathrm{C}$. As placas foram lavadas com tampão PBS-Tween 20 (PBS- T), bloqueadas com PBS-T- ${ }_{0,1 \%}$ leite ${ }_{5 \%}$ por uma hora a $37^{\circ} \mathrm{C}$ e 18 horas a $4^{\circ} \mathrm{C}$, em seguida foram lavadas com PBS-T (5x). Para a realização dos testes foram adicionados $100 \mu \mathrm{l}$ de cada amostra de soro diluído $1 / 400$, sendo 4 soros controles positivos e 7 soros controles negativos, em cada placa e incubados por uma hora a $37^{\circ} \mathrm{C}$. As placas foram então lavadas com PBS-T $(5 x)$ e incubadas com o conjugado anti-humano IgG $(100 \mu \mathrm{l}, 1 / 2000$, Sigma) por uma hora a $37^{\circ} \mathrm{C}$, lavadas com tampão PBS-T (5x) e a seguir adicionadas da solução do substrato $(5 \mathrm{mg}$ orthophenylenediamine, $10 \mathrm{ml}$ de tampão citrato $0,1 \mathrm{M}$ ) por 5 a 10 minutos. A reação foi interrompida pela adição de ácido $\mathrm{H}_{2} \mathrm{SO}_{4} 4 \mathrm{~N}$ e a leitura da densidade ótica feita em $490 \mathrm{~nm}$. Todas as reações foram realizadas em duplicatas e repetidas em dois dias diferentes.

A análise estatística foi feita com os valores de densidade ótica (DO) com cada um dos 680 soros, pelo método de K-médias em análise de cluster, o que permitiu o agrupamento da população em dois grupos. O grupo 1 representado pelos indivíduos considerados reatores e o grupo 2 pelos não reatores.

\section{RESULTADOS}

Foram analisados 680 soros de doadores de sangue, sendo 170 de cada um dos municípios Campo Mourão, Cianorte, Maringá e Umuarama, todos localizados na Região Noroeste do Paraná como mostra a Figura 1.

A população estudada foi constituída por indivíduos saudáveis, com idade média de 28 anos, sendo $70 \%$ pertencente ao sexo masculino e apenas $12 \%$ residente em zona rural. Detalhes destes dados, apresentados por município de origem, podem ser observados na Tabela 1.
Admitiu-se como sensibilizados os soros que apresentaram DO acima do dobro da média dos controles negativos, denominado em sorologia ponto de exclusão ou cut-off. Para essa interpretação, foram determinados arbitrariamente, como negativos os valores obtidos com soros de doadores residentes em Curitiba.

Levando em conta esse valor de corte, determinamos que $27 \%$ dos indivíduos apresentaram anticorpos anti $P$. brasiliensis acima desse nível e, para efeito de interpretação foram considerados 
Tabela 1 - Distribuição quanto ao sexo, residência, faixa etária e procedência de 680 doadores de sangue residentes na região Noroeste do PR, cujos soros foram avaliados quanto à presença de anticorpos anti Paracoccidioides brasiliensis. Março de 2000.

\begin{tabular}{|c|c|c|c|c|c|c|c|c|c|c|c|c|}
\hline \multirow[b]{3}{*}{ Município } & \multicolumn{4}{|c|}{ Sexo } & \multicolumn{4}{|c|}{ Residência } & \multicolumn{4}{|c|}{ Idade anos } \\
\hline & \multicolumn{2}{|c|}{ masculino } & \multicolumn{2}{|c|}{ feminino } & \multicolumn{2}{|c|}{ rural } & \multicolumn{2}{|c|}{ urbana } & \multicolumn{2}{|c|}{$18-29$} & \multicolumn{2}{|c|}{$\geq 30$} \\
\hline & $n^{\circ}$ & $\%$ & $n^{\circ}$ & $\%$ & $\mathrm{n}^{\circ}$ & $\%$ & $n^{\circ}$ & $\%$ & $n^{\circ}$ & $\%$ & $n^{\circ}$ & $\%$ \\
\hline Campo Mourão & 114 & 67 & 56 & 33 & 32 & 19 & 138 & 81 & 45 & 26 & 125 & 74 \\
\hline Maringá & 115 & 68 & 55 & 32 & 13 & 8 & 157 & 92 & 67 & 39 & 103 & 61 \\
\hline Umuarama & 137 & 81 & 33 & 19 & 24 & 14 & 146 & 86 & 70 & 42 & 100 & 58 \\
\hline Cianorte & 108 & 64 & 62 & 36 & 15 & 9 & 155 & 91 & 65 & 38 & 105 & 62 \\
\hline Total & 474 & 70 & 206 & 30 & 84 & 12 & 596 & 88 & 247 & 36 & 433 & 64 \\
\hline
\end{tabular}

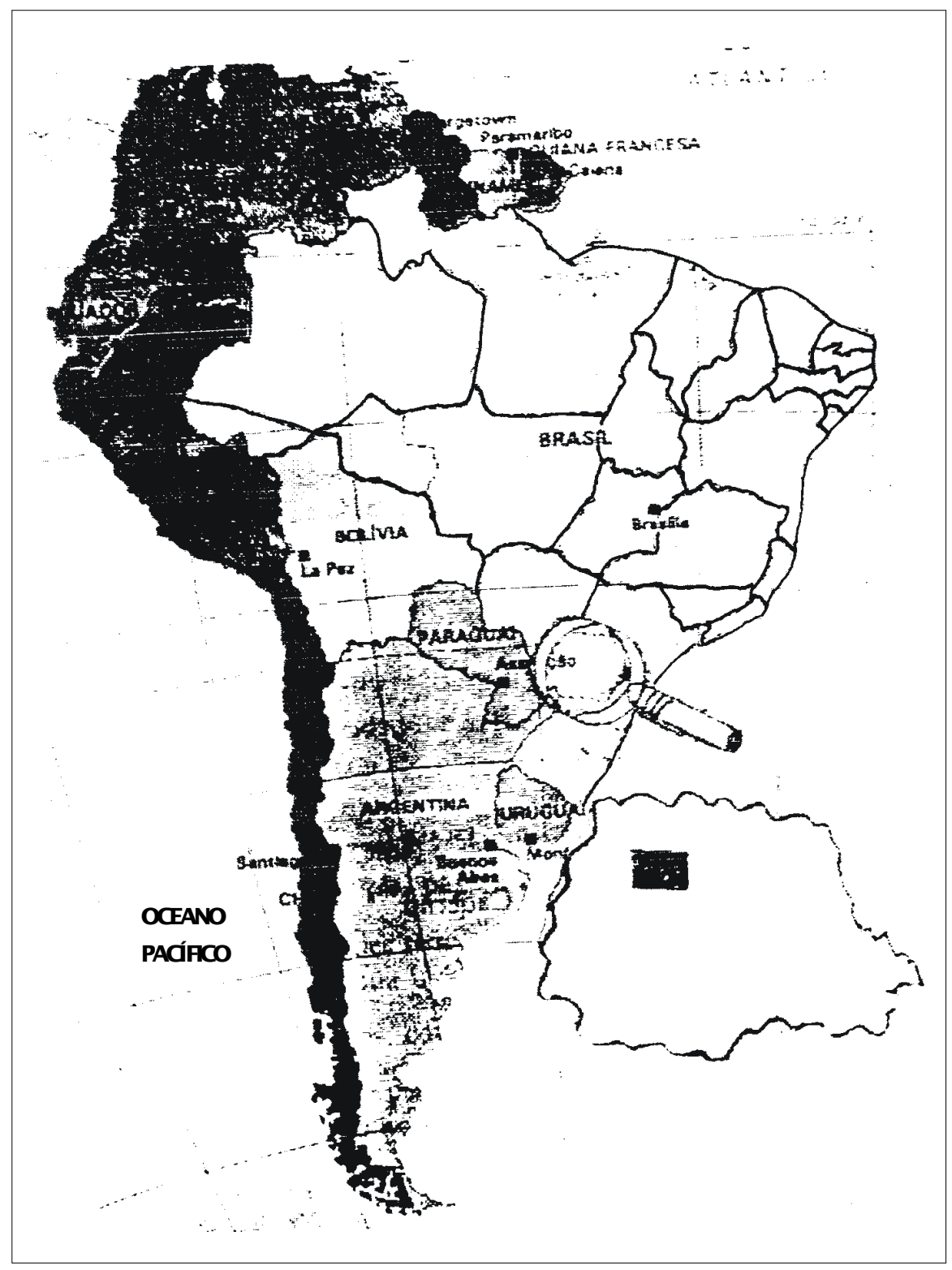

Figura 1 - Mapa da América do Sul evidenciando a Região Noroeste do Estado do Paraná, Brasil. 
sensibilizados, enquanto que os valores abaixo dessa faixa de corte, $73 \%$ dos soros, foram considerados não sensibilizados.

A Figura 2 mostra esses dados distribuídos conforme o município de origem, compreendendo indivíduos provenientes de Campo Mourão, de Maringá, de Cianorte e de Umuarama.

A Tabela 2 apresenta os valores de leitura (DO) mínimos e máximos, além da média e desvio padrão encontrados para cada grupo.

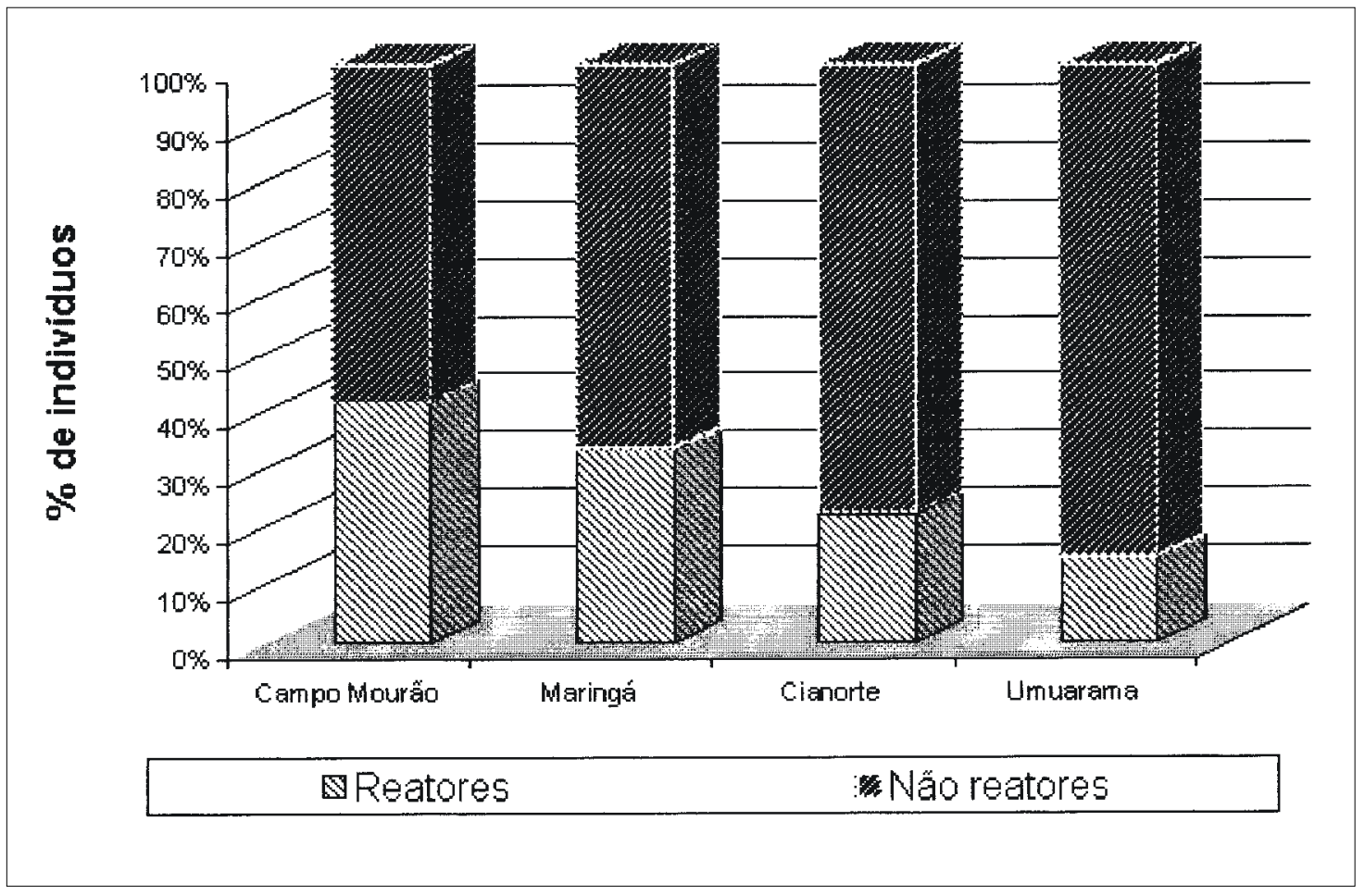

Figura 2 - Distribuição dos doadores de sangue da Região Noroeste do Paraná segundo município de origem e reatividade aos antiggenos de Paracoccidioides brasiliensis, março de 2000.

Tabela 2 - Distribuição dos resultados obtidos, em densidade ótica, pela reação de ELISA em 680 soros de doadores de sangue de quatro municípios da Região Noroeste do PR. Março de 2000.

\begin{tabular}{|c|c|c|c|c|c|c|c|}
\hline \multirow[b]{2}{*}{ Município } & \multirow[b]{2}{*}{ Grupo* } & \multirow[b]{2}{*}{ № } & \multirow[b]{2}{*}{$\%$} & \multicolumn{3}{|c|}{ densidade ótica } & \multirow[b]{2}{*}{$\pm \mathrm{DP}$} \\
\hline & & & & Média & mín & máx & \\
\hline \multirow[t]{2}{*}{ Campo Mourão } & S & 67 & 39 & 2,86 & 2,065 & 3.857 & 0.4755 \\
\hline & NS & 103 & 61 & 1.105 & 0.101 & 1.957 & 0.457 \\
\hline \multirow[t]{2}{*}{ Maringá } & $\mathrm{s}$ & 53 & 31 & 2.40 & 1.752 & 3.499 & 0.514 \\
\hline & NS & 117 & 69 & 1.062 & 0.186 & 1.694 & 0.377 \\
\hline \multirow[t]{2}{*}{ Umuarama } & $\mathrm{s}$ & 24 & 14 & 1.354 & 0.892 & 2.72 & 0.548 \\
\hline & NS & 146 & 86 & 0.414 & 0.133 & 0.826 & 0.168 \\
\hline \multirow[t]{2}{*}{ Cianorte } & $\mathrm{S}$ & 37 & 22 & 2.029 & 1.365 & 4.409 & 0.681 \\
\hline & NS & 133 & 78 & 0.660 & 0.106 & 1.321 & 0.298 \\
\hline
\end{tabular}

*Grupo - S: soros com níveis de anticorpos acima do valor de corte ou cut off

NS: soros com níveis de anticorpos menores ou iguais ao valor de corte ou cut off

\section{DISCUSSÃO}

Considerando que PCM não é doença de notificação obrigatória, é desconhecida sua real prevalência e incidência. Contudo, as características climáticas, fisiográficas e o elevado número de casos diagnosticados permitem considerar a Região Noroeste do PR como endêmica para paracoccidiodomicose. Porém, essa idéia, considerada como consensual pela comunidade científica, baseia-se em evidências, pois tem sido restrita a relatos de casos esporádicos ${ }^{6}$. As reserváreas de $P$. brasiliensis ${ }^{2}$ são compatíveis com as características observadas na Região Noroeste do PR. 
O fungo $P$. brasiliensis parece crescer no solo como sapróbio permanente ${ }^{15}$. Aceita-se que nessas condições atinge o homem, por via inalatória. A progressão de infecção para doença depende de fatores relacionados tanto ao agente quanto ao hospedeiro e pode ocorrer depois de vários anos. Dessa forma, as manifestações clínicas da micose apresentam-se, na maioria das vezes, em pessoas acima dos 30 anos, apesar do contato inicial do hospedeiro com o fungo ter ocorrido durante as primeiras décadas de vida.

No Estado do Paraná, a história da PCM é pouco documentada. Mota ${ }^{11}$ mostrou que dos 57 pacientes diagnosticados com PCM em Curitiba, 35\% eram casos autóctones da doença, sendo que 20 pacientes residiam no Noroeste do Paraná.

Mais recentemente, inquéritos epidemiológicos foram realizados sugerindo sensibilização da população aos antígenos de P. brasiliensis. Rebelatto ${ }^{14}$ usando a paracoccidioidina em testes intradérmicos obteve índice de $51 \%$ de positividade em 104 indivíduos sadios da região metropolitana de Curitiba.

O mesmo teste empregando o antígeno purificado, a gp43, demonstrou $50 \%$ de sensibilidade em população rural de Londrina, $\mathrm{PR}^{16}$ e $43 \%$ em operários de uma usina de álcool residentes em dois municípios da Região Noroeste do $\mathrm{PR}^{6}$.

Os estudos sobre a epidemiologia da PCM são baseados em inquéritos com a reação intradérmica de leitura tardia, a intradermorreação ${ }^{5}$. Porém trata-se de metodologia complexa, invasiva e requer grande número de voluntários com complicações de ordem ética. No presente trabalho avaliamos a possibilidade do emprego de reação sorológica como forma alternativa para indicar a sensibilização de indivíduos saudáveis a antígenos de P. brasiliensis.

A inclusão dos doadores no presente estudo respeitou a rotina do Hemocentro, dessa forma a amostra torna-se representativa da população regional, pois inclui um grupo heterogêneo constituído por indivíduos que se apresentaram espontaneamente e desenvolvem vários tipos de atividades, diferentes idades, sexo, hábitos sociais, econômicos e culturais.

Conforme a Tabela $1,87 \%$ dos doadores eram provenientes de zona urbana. Ao analisar essa observação, é preciso considerar as características próprias de municípios pequenos, onde os limites entre zona urbana e rural são demasiadamente tênues. É permitido assumir que todos os indivíduos amostrados foram expostos ao $P$. brasiliensis, independente de relatar residência em zona rural. Na verdade, todas as pessoas nessas cidades desenvolvem algum tipo de contato com ambientes rurais, mesmo que para lazer, ou estão em contato contínuo com partículas de solo em suspensão através da poeira e vegetação.

O teste de ELISA foi o escolhido por apresentar alta sensibilidade em estudos sobre a $\mathrm{PCM}^{4}{ }^{9}$ e por ser utilizado para triagem sorológica em serviços de hemoterapia. O uso de antígeno com expressiva quantidade de gp43, como foi o caso, é importante na busca de alto grau de especificidade pois essa molécula induz resposta de anticorpos em 100\% dos pacientes portadores de PCM o que não ocorre com soro de indivíduos normais ${ }^{13}$.

Entretanto, tendo em vista a alta sensibilidade da técnica de ELISA, não pode ser descartada a possibilidade de reações cruzadas especialmente com histoplasmose, leishmaniose e doença de Chagas ${ }^{1317}$, doenças comuns na região.

O índice médio de soros com níveis de anticorpos acima do atribuído como corte, para o presente trabalho foi de $27 \%$. Este dado parece relevante como indicativo da presença de P. brasiliensis na região, pois segundo Londero $\&$ Del Negro ${ }^{10}$, podem ser considerados como portadores de infecções assintomáticas os indivíduos clinicamente sadios com sorologia positiva para PCM, sobretudo entre moradores de áreas endêmicas para a doença.

Essas considerações, corroboradas por nossos achados, tornam possível admitir que o teste de ELISA poderia ser indicado para substituir, com superioridade, as intradermorreações utilizadas em estudos de inquéritos epidemiológicos sobre PCM. Destaca-se entre as vantagens o fato de não ser invasivo, permitir grandes amostragens e sobretudo por indicar a sensibilização recente do indivíduo, refletindo dessa forma maior fidedignidade com relação à região amostrada. As freqüentes migrações observadas na população de nosso país dificultam a interpretação dos resultados com testes intradérmicos que se baseiam na imunidade celular, essa é mantida por longos períodos, podendo refletir sensibilização ocorrida no passado, talvez em região geográfica distante da amostrada.

Os resultados por nós obtidos deverão servir de alerta aos clínicos, pois a PCM é de alta relevância em Saúde Pública. Segundo Londero e Del Negro ${ }^{10}$, nas áreas endêmicas essa doença deveria ser levada em consideração no diagnóstico diferencial de todo paciente com infecção respiratória aguda ou crônica. Esses autores recomendam ainda a inclusão de técnicas sorológicas para triagem rotineira em pacientes dos serviços de pneumologia e outras doenças do tórax. A positividade sorológica obrigaria à repetição de exames micológicos para demonstrar o agente, o que às vezes, requer vários exames em dias consecutivos.

\section{AGRADECIMENTOS}

Os autores agradecem a Dra Elaine Guadelupe Rodrigues e ao Dr Zoilo Pires de Camargo, Escola Paulista de Medicina/ UNIFESP pelo apoio, discussão e interpretação dos resultados de ELISA e ao último por também ter cedido e testado o antígeno empregado no presente trabalho. Aos doadores de sangue, nossa gratidão e o pedido da benção de DEUS. 


\section{REFERÊNCIAS BIBLIOGRÁFICAS}

1. Almeida IC, Neville DC, Mehlert A, Treumann A, Ferguson MA, Previato JO, Travassos LR. Structure of the linked oligosaccharide of the main diagnostic antigen of the pathogenic fungus Paracoccidioides brasiliensis. Glycobiology 6:507-515, 1996.

2. Borelli D. Concepto de reservarea. La reducida reservarea de la paracoccidioidosis. Revista de Dermatologia de la Venezuela 4:71-77, 1964

3. Brummer E, Castaneda E, Restrepo A. Paracoccidioidomycosis: an update. Clinical Microbiology Reviews 6:89-117, 1993.

4. Camargo ZP, Guesdon SL, Drouhet E, Improvisi L. Enzymelinked immunosorbent assay (ELISA) in paracoccidioidomycosis. Comparison with counterimmunoelectro-phoresis and erythroimmunoassay. Mycopathologia 88:31-37, 1984.

5. Fava N. Imunologia da PCM. Revista do Instituto de Medicina Tropical de São Paulo 18:42-43, 1976.

6. Fornajeiro N, Svidzinski TIE. Paracoccidioidomicose: Inquérito epidemiológico com gp43 em dois Municípios do Nordeste do Paraná. In: Anais do III Congresso de Farmácia e Análises Clínicas de Maringá, Paraná, p.67, 1999.

7. Fundação Instituto Brasileiro de Geografia e Estatística. Censo demográfico. Maringá, 1991.

8. Greer DL, Restrepo A. La epidemiologia de la paracoccidioidomicosis. Boletin de la Oficina Sanitaria Panamericana 82:428-443, 1977.

9. Londero AT, Wanke B. Epidemiology and Paracoccidioidomycosis Infection. In: Franco M, Lacaz CS, Restrepo-Moreno A, Del Negro G. Paracoccidioidomycosis. CRC Press, Boca Raton, p.109-120, 1994.

10. Londero AT, Del Negro G. Paracoccidioidomicose- patogenia, formas clinicas, manifestações pulmonares e diagnóstico, tratamento. Jornal de Pneumologia 12:41-60, 1986.
11. Mota CCS. Contribuição ao estudo da epidemiologia da Blastomicose Sul Americana no Paraná. Faculdade de Medicina da Universidade Federal do Paraná, Curitiba, PR, 53-92,19661967.

12. Padilha-Gonçalves A. Epidemiological factors in paracoccidioidomycosis. Pan American Health Organization. Scientific Publication 254:53-58, 1972.

13. Puccia R, Travassos LR. 43 kilodalton glycoprotein from Paracoccidioides brasiliensis: immunochemical reactions with sera from patients with paracoccidioidomycosis, histoplasmosis or Jorge Lobo disease. Journal of Clinical Microbiology 29:1610 1615, 1991.

14. Rebelatto CLK. Estudo da associação entre os antígenos HLA$A, C, D R$ e $D Q$ e a paracoccidioidomicose infecção. Dissertação de mestrado, Universidade Federal do Paraná, Curitiba, PR, 1996.

15. Restrepo A. The ecology of Paracoccidioides brasiliensis a puzzle still unsolved. Journal of Medical and Veterinary Mycology 23:323334, 1985.

16. Somensi DC, Itano EN, Camargo ZP, Oliveira OLP. A utilização da gp43 de Paracoccidioides brasiliensis em testes intradérmicos na região de Londrina-PR.In: Anais do VI Encontro de Iniciação Científica, Ponta Grossa, PR, 1997.

17. Suzuki E, Toledo MS, Takahashi HK, Straus AH. A monoclonal antibody directed to terminal residue of b-galactofuronase of a glycolipid antigen isolated from Paracoccidioides brasiliensis: cross-reactivity with Leishmania major and Trypanosoma cruzi. Glycobiology 7: 463-468, 1997. 